\title{
Contents
}

\section{In Part 1}

Introduction

1. The beginning

2. Of landers and orbiters

3. The grandest tour

\section{In Part 2}

4. The decade of Halley

5. The era of flagships

6. Faster, cheaper, better

\section{Now in Part 3}

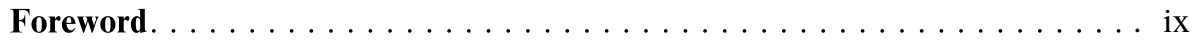

Author's preface $\ldots \ldots \ldots \ldots \ldots \ldots \ldots \ldots \ldots \ldots \ldots \ldots \ldots \ldots \ldots$

Acknowledgments $\ldots \ldots \ldots \ldots \ldots \ldots \ldots \ldots \ldots \ldots \ldots \ldots \ldots \ldots$

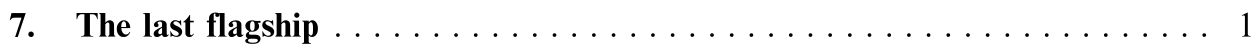

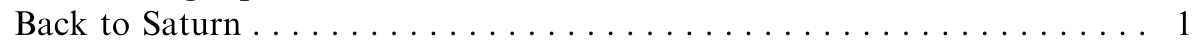

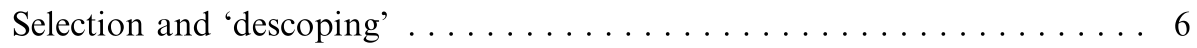

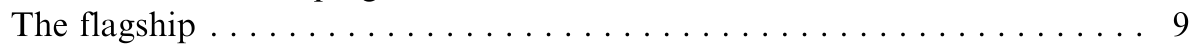

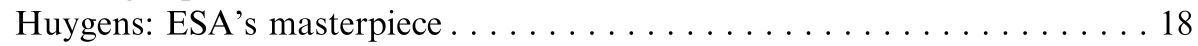

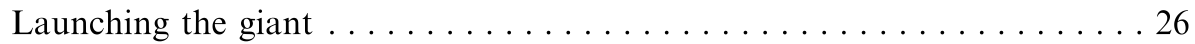

The long cruise . . . . . . . . . . . . . . . . . . . . . . . 29

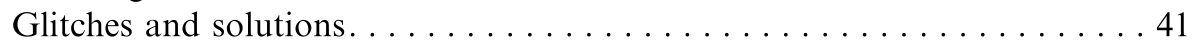

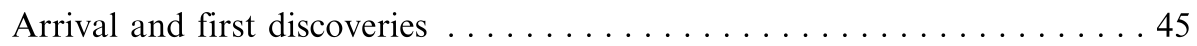

Huygens' descent . . . . . . . . . . . . . . . . . . . . . . . 74

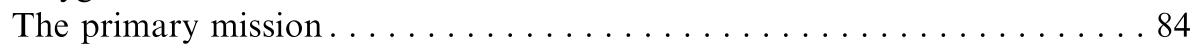

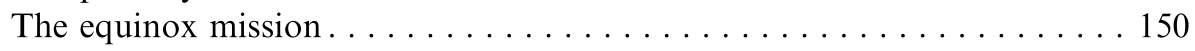

The solstice mission and finale . . . . . . . . . . . . . . 179 


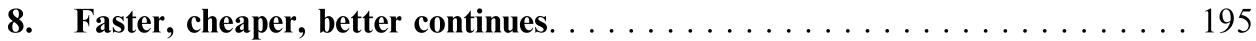

A landmark year. . . . . . . . . . . . . . . . . . . . . 195

Star Trek propulsion. . . . . . . . . . . . . . . . . . . . . 196

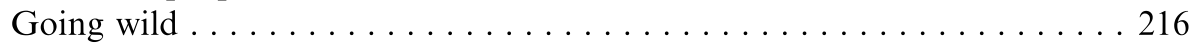

Faster, cheaper, worse. . . . . . . . . . . . . . . . . . . . 242

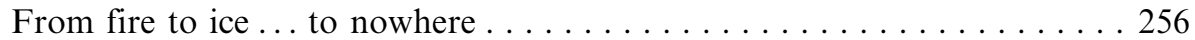

The wounded falcon . . . . . . . . . . . . . . . . . . . 261

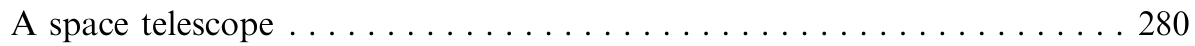

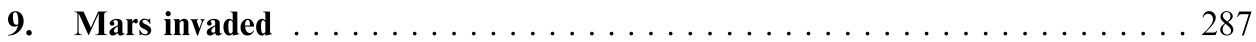

Losing hope . . . . . . . . . . . . . . . . . . . . . . . . . . . . . . 287

Dinner for the 'Cosmic Ghoul' . . . . . . . . . . . . . . . . . . . . . . . 294

Canceled Surveyors. . . . . . . . . . . . . . . . . . . . . . 307

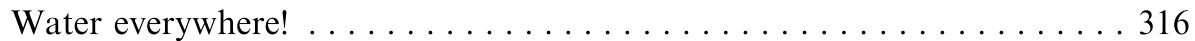

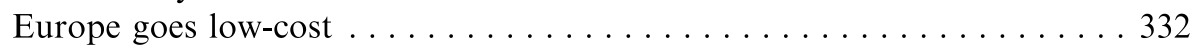

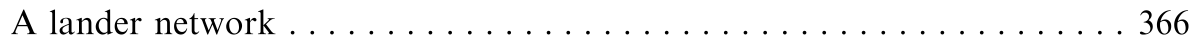

Blueberries on Mars . . . . . . . . . . . . . . . . . . . . . . . . . 369

The robots that did not want to die ................. 405

Glossary . . . . . . . . . . . . . . . . . . . . . . . . . . . . . . . 469

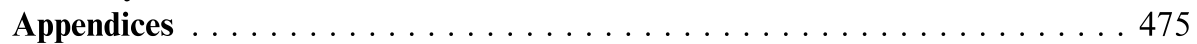

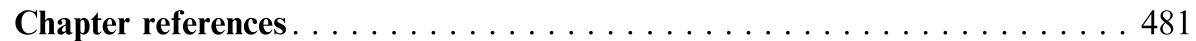

Further reading . . . . . . . . . . . . . . . . . . . . . . 515

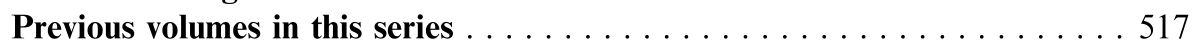

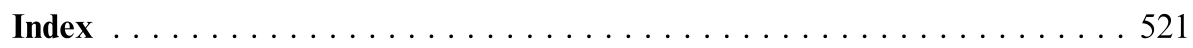

